\title{
Spiral Tube of Schchowa
}

National Cancer Institute

\section{Source}

National Cancer Institute. Spiral Tube of Schchowa. NCI Thesaurus. Code C33594.

The portion of the renal tubule located inside the renal cortex between the proximal convoluted tubule and the loop of Henle. 